\title{
SEDIMENT DEPOSITION IN KOYNA RESERVOIR BY INTEGRATED
} BATHYMETRIC SURVEY

\author{
R. A. Patil ${ }^{1}$, R. V. Shetkar ${ }^{2}$ \\ ${ }^{1}$ Research Scholar, Government College of Engineering, Aurangabad (Associate Professor, Dept. of Civil \\ Engineering, DKTE's Textile and Engineering Institute, Ichalkaranji-416115), Maharashtra, India \\ rapatildkte@yahoo.co.in \\ ${ }^{2}$ Associate Professor, Dept. of Civil Engineering, Government College of Engineering, Aurangabad, Maharashtra, \\ India \\ rvshetkar@yahoo.com
}

\begin{abstract}
In southern part of India, most of the precipitation occurs due to south-west monsoon during the months of June to September. Storage reservoirs are constructed to store the run-off volume and utilize it for long term requirements in the command such as irrigation, power generation, domestic water supply etc. The sediment deposition in the reservoir is a continuous and complex process. Sediment in a river which originates from the land erosion process in the catchment is propagated along with the river flow and finally gets deposited in the reservoir. This has adverse effect such as reduction in storage capacity and increase in backwater levels. For the long term and yearly planning of efficient utilization of reservoir capacity, estimation of sediment deposit is not only sufficient but also estimation of trapped sediment at different levels in the reservoir is required. Differential Global Positioning System (DGPS) based Integrated Bathymetric Survey System for hydrographic survey is used for estimation of sediment deposition pattern in the Koyna reservoir. In this method three or more satellite based GPS receivers are used in differential mode for positioning. Ecosounder is used for depth measurements. GPS reference receiver is located at a known latitude and longitude position and GPS mobile receiver is located on the survey boat. Both the GPS operate in differential mode through a communication link. From this study (2004) it is observed that sedimentation rate in Koyna reservoir is more than 6.5 Ham/100 sq. km/year anticipated in 1949.
\end{abstract}

Key Words: reservoir, sedimentation, Bathymetric Survey, hydrographic, GPS

\section{INTRODUCTION}

Release of bed load and deposition of suspended materials carried by inflow in the reservoir comprise the sedimentation process. Sedimentation is a phenomenon due to which capacity of reservoir reduces with lapse of time. This phenomenon of sedimentation mainly depends upon area, topography, rainfall, agriculture pattern and forest in catchments area. The sediment deposition has adverse effect such as reduction in storage capacity, increase in back water level, formation of shoals. For effective planning and use of stored water optimally it is necessary to find the actual rate of sedimentation and revised capacity of reservoirs. Therefore hydrographic survey (sedimentation survey) is to be carried out periodically for every reservoir. Conventional method, Remote sensing technique and DGPS based Integrated Bathymetric Survey are used to determine the storage capacity of reservoirs. In the conventional method conventional equipment like theodolite, level, sextant, range finder, sounding rods, echo-sounders, current meter, motor boat etc. are employed. Predetermined cross sections are marked by constructing range monuments on either side of the bank. Hydrographic survey is carried out along these range lines.

Reservoir sedimentation survey by using Remote Sensing Technique is essentially based on mapping of water spread areas at the time of satellite over pass. Reduction in capacity of reservoir at different levels is depicted by reduction in water spread area at different water levels. The water-spread areas measured from the Satellite Imageries are used to calculate the value of water stored between different levels. The recent development in field of sedimentation survey comprises use of IBS consisting of digital echo-sounder, DGPS for accurate positioning, computer \& software for collecting data and analysis of data. Using Navisoft and Surfer software, the sedimentation survey becomes easy, accurate and time saving. It also provides pictorial presentation of contour map and bottom morphology of the reservoir. The present survey is conducted by Maharashtra Engineering Research Institute, Nashik, Maharashtra.

\section{DGPS BASED INTEGRATED BATHYMETRIC SURVEY SYSTEM}

\subsection{System Configuration}

DGPS based hydrographic survey system comprises the following: (figure nos. 1 to 6 )

1. Global Positioning System in different mode (Reference and Mobile Station).

2. Echosounder for depth data collection 
3. Personal Computer system with Helmsman's Display, lap-top, VHF radio

4. Hydrographic survey software for the survey planning, navigation, data collection and post processing of the collected data.

5. Motorised boat as mobile station fitted in with Helmsman's Display, lap-top, VHF radio.

6. Supporting facilities like UPS, batteries, safety equipments etc.

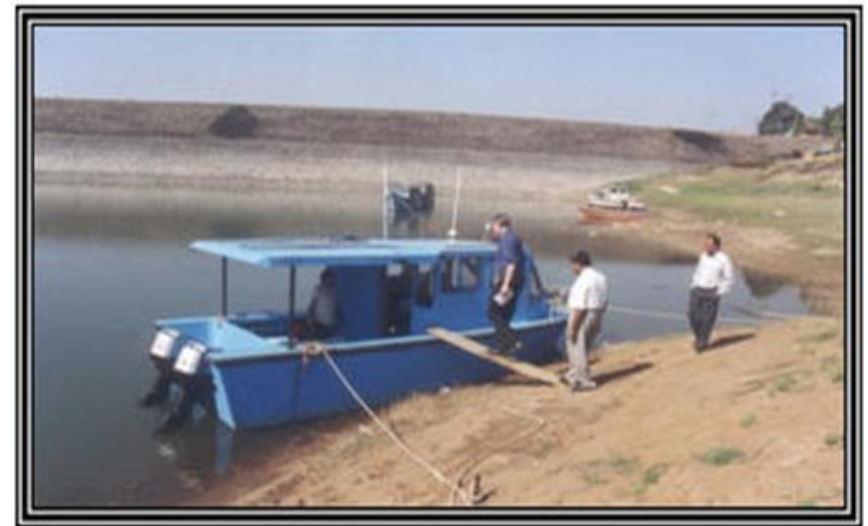

Figure 1: FRP Boat with Trailer

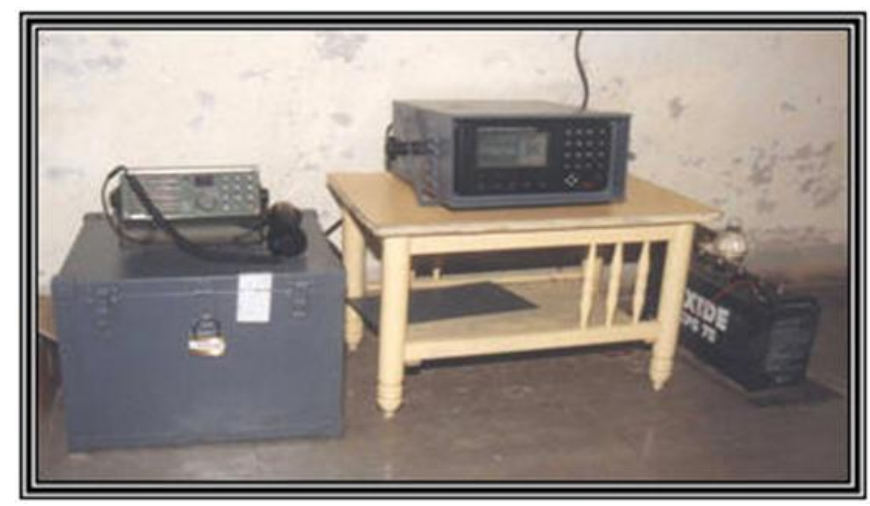

Figure 2: Reference Station (DGPS)

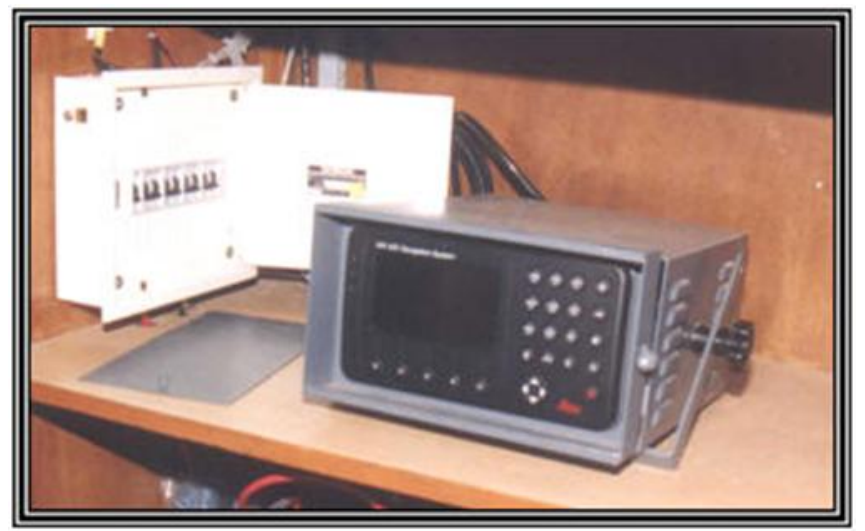

Figure 3: Mobile Station (GPS)

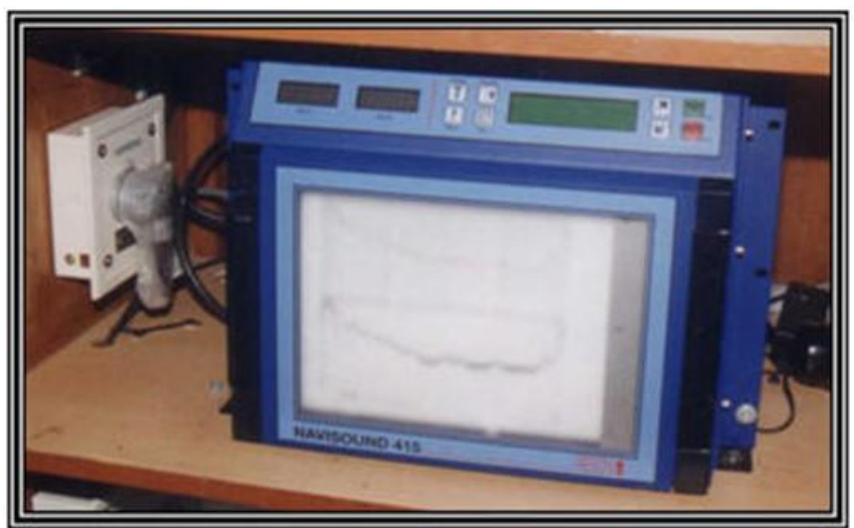

Figure 4: Echo Sounder

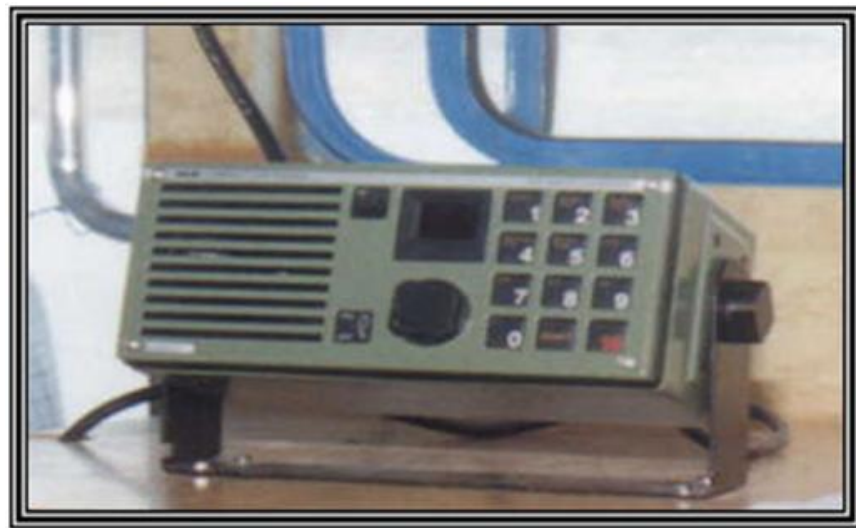

Figure 5: VHF Voice Radio

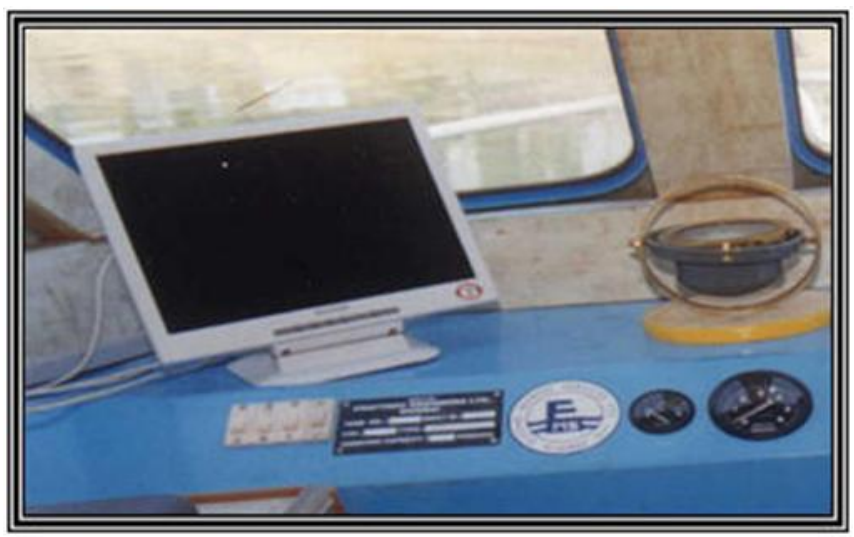

Figure 5: Helmsman's Display

\subsection{Global Positioning System}

Navigation System with Timing and Ranging Global Positioning System (NAVSTAR GPS) is all weather, space borne navigation system. It is designed to accurately determine the position, velocity and time in common reference system; GPS signals are available to the user anywhere on or near earth on continuous basis. The Global Positioning system consists of three segments.

1. The Space segment consisting of satellite constellation which broadcast signals.

2. The control segment from where the entire system is monitored and steered called as Reference Station. 
3. The User segment includes GPS receivers called as mobile unit.

The space segment is arranged such that at least four satellites are in view at any location on the earth 24 hours a day. The satellite constellation is continuously monitored and steered at least once in a day by the control segment located on the earth. The user segment consists of GPS Receivers which continuously track signals from satellites in view and determines pseudo ranges to the satellites using either code phase or carrier phase measurement technique. Using pseudo ranges from four satellites the GPS navigation algorithms estimate three dimensional position of the receiving antenna which is displayed by the GPS receiver.

\subsection{Differential Operation of the GPS}

For differential operation two GPS receivers are used. Receiving antenna of the reference GPS is installed at a known position and the position of the mobile GPS receiving antenna is determined. At least four common satellites are required to be tracked by both the receivers. The known position of the reference receiver is used to calculate corrections to the observed code ranges. These corrections are transmitted to the mobile receiver via UHF/VHF communication link. The mobile receiver applies these corrections in the computations and evaluates the position accurately. The position accuracy of $1 \mathrm{~m}$. can be achieved with differential operation of GPS. This capability is primarily based on the fact that GPS error sources are very similar over a region of say $500 \mathrm{~km}$ and are therefore virtually eliminated by differential technique. Data communication link is essential component of DGPS. It requires compatible hardware at both reference and mobile stations. The pseudo range correction update rate of $10 \mathrm{sec}$. or better is required to get the desired accuracy.

\section{RESERVOIR SURVEY PREPARATION}

Koyna reservoir survey preparation has been done in following stages.

1. Installation of DGPS reference station.

2. Launching of boat and installation of mobile station.

3. Installation of Echosounder and SVP.

4. Installation of data acquisition PC and Helmsman display.

5. Preparation with Navisoft survey software.

\subsection{Installation of DGPS Reference Station}

The accuracy in the position is increased with the differential global positioning system involving the reference station and the mobile station. The first step in the DGPS based reservoir survey planning is to select the suitable location for establishing GPS reference station preferably at the known coordinates and from where the GPS antenna will have clear sky view. The reference station was initially set up at the Koyna dam and then along the periphery of Koyna reservoir. The complete reference station set up comprising of GPS MX 9250 receiver, GPS choke ring antenna, UHF data communication link with
UHF antenna, VHF voice radio unit with VHF antenna and batteries were installed. GPS receiver has in-built menu driven software which was used to initialize the GPS set up and monitor the receiver status on display. The reference station was configured as Navigator for the self-survey mode and deployed for more than 24 hours. The reference station was then configured as RS mode for transmitting the correction.

\subsection{Launching the Boat and Installation of the}

\section{Mobile Station.}

The survey boat with twin mounted $60 \mathrm{HP}$ engine was launched with the help of the boat trailer and tractor in the water and a suitable jetty place was selected for the boat. The boat mounted equipment the GPS mobile station MX420 with smart GPS antenna, UHF data link with UHF antenna, VHF voice radio unit with VHF antenna, batteries of boat engine, and batteries of equipment were installed and connected to the switch panel. The survey boat is also fitted with the small navigation Echosounder for the boat driver. The mobile station GPS receiver was switched on. The reception of the satellite signals and the corrections from the reference station were observed and verified.

\subsection{Installation of the Echosounder and SVP}

Echosounder NAVISOUND NS 415 was installed in the boat. The sound velocity probe SVP-15 is installed to determine the sound velocity in the water. The SVP probe was lowered at different depths and the average reading of the sound velocity is taken. The sound velocity is input to the echosounder in the echosounder set up. The echosounder calibration check was done using bar check procedure for different depths. The transducer was fitted to the transducer well provided in the boat properly and connected to the echosounder. The necessary settings of the initial lock out for channels, draught, Tx power and receiver gain were done in the echo sounder set up menu.

\subsection{Installation of the data acquisition PC and}

\section{Helmsman display}

A laptop installed with navitronic software, Navisoft was used for the hydrographic survey work. Mobile GPS is interfaced with the echosounder AUXIN port. The echosounder is interfaced with the laptop. The laptop used, has inbuilt VGA port which is interfaced with the additional LCD monitor (Helmsman display) for the boat driver to view the range lines to be surveyed.

\subsection{Preparation with the Navisoft software}

The Bathymetric survey software used consists of various modules to support the survey activities as Planning and Presentation, Survey, Calculate, Data edit, Data exchange. The Planning and Presentation module provides graphical aids for creation of the survey design. It has various options as Chart set up, Header set up, Object set up, Segment set up, Symbol set up, and Grid set up. 
A chart with suitable dimensions is selected in the chart set up. To plan the survey, the coordinates of two points parallel to the dam were taken in UTM system, one point at left bank and another at the right bank and a reference line was drawn. It was not convenient to create a single chart for whole reservoir. Hence the reservoir area was divided into different 11 charts as per the physical situation of reservoir so that the part to be surveyed is covered in that chart. This was done with the help of chart set up programme. The range lines with different spacing $(200 \mathrm{~m}, 250 \mathrm{~m}, 300 \mathrm{~m}$ and $350 \mathrm{~m}$ ) were generated with the Auto lines option in the segment set up covering all the survey area in each chart. Additional lines required to cover the reservoir area were manually drawn on the chart. The creation of the header and symbol is optional. Each chart was saved as the project file, which was used as the survey plot during the data collection.

\subsection{Data Collection}

The Survey module in the software supports variety of input/output devices such as DGPS, Echosounder etc. The device drivers for echosounder and DGPS were enabled and communication parameters were specified to establish data communication. The input coordinates and output coordinates settings such as datum, zone was done. The software provides the facility to test the raw data logging from the echosounder and the DGPS. The data logging files were created with the data log file set up. The data-logging mode was configured to be continuous. The software provides automatic creation and storage of the data files during the survey.

\subsection{Daily Procedure of the survey}

During the reservoir survey, daily water level data were collected near the dam at the start of the survey. The water level is required for transforming the depth data into reservoir level in elevation. The boat and the equipment batteries are checked for proper voltage. The fuel tanks and the engines are checked for the operation. The availability of the life jackets, buoys is also checked. The determination of sound velocity in the water and the calibration of the echosounder with the BAR CHECK were done every day. The power connection, antenna connections and the interface connections were checked. The complete system was switched on and made ready for the data collection under manual control. The different presentation options available in the software like Track Plot, Alphanumeric display, Speed bar (function status/alert bar), Left Right indicator, and echo trace were enabled and arranged on the PC screen to monitor different survey activities. The duplicate presentation options like Track plot 2, left right indicator 2 and the alphanumeric 2 were enabled and arranged on the Helmsman display for the boat driver for proper navigation.

\subsection{Run Line Procedure}

The range line is selected which is shown in different colour on the track plot screen and the boat is moved to the beginning of the selected line as close to the bank as possible. After positioning the boat on the line, the data logging was started. The boat driver was guided to position the boat on the selected track with the help of Helmsman's display. The boat speed of 3-5 knots was maintained. The software automatically recorded the position and depth data at the distance interval set in the data file. The boat was moved to the end of line as close to the bank as possible. The range line survey activities were recorded in the logbook. Next line was selected and the procedure was repeated for the all the range lines.

\subsection{End of the Day Procedure}

At the end of the day the raw data and the PRD data files were viewed and back-up copies of the same were taken. All the equipments were switched off. The batteries were put for charging for next day's work. The boat engines and the fuel tanks were secured properly. The boat was parked at the suitable place alongside the bank with help of coir fenders and ropes. The survey area of about $125 \mathrm{sq}$. Km inclusive of about 550 range lines was completed within one month.

\subsection{Data Processing}

The raw data file contains the depth, XY position, time tag and other surveyed related information. The calculate module in the software converts the raw file to the product file after applying corrections and filtering. Data containing depth and XY position is used for further analysis.

\subsection{Data Preparation}

The spurious echo readings those occur because of various reasons, such as underwater inhabitants crossing the sonic beam or reflections from suspended materials. This can be observed as overshoots, undershoots or spikes in the depth data collected along the survey line. These spurious data readings can be removed with the help of Data Edit module in the software. This module generates the profile/crosssection views of the survey lines. The edited data files were stored in the DATALOG directory of the software. The data file was transformed to the STAR DOT format with the help of DATA EXCHANGE module provided in the software, which is used for further processing and analysis in the processing software SURFER.

\subsection{Data Analysis}

The data file is opened in the SURFER software and viewed. The depths are transformed to the true ground elevation with respect to MSL. The corresponding reservoir water level data recorded in the logbook was applied to the readings. The shallow regions of the reservoir approximately above $1.5 \mathrm{~m}$ could not be surveyed, as it was not possible to manoeuvre the boat in these regions. The bank distances recorded in the log book were used for linear interpolation of the intermediate data between the end point bed elevation on the survey line and the water level elevation on the survey line and the water level elevation recorded for the corresponding day. The final data file is then converted into the GRID file with the GRID DATA module in the software. The proper grid limits and spacing 
were applied. The Triangulation interpolation method was used for the conversion. The Grid file used to generate various maps like contour map, 3D wireframe, and 3D surface map with the MAP option available in the software for the presentation of the generated maps. The volume and area calculations are done using the GRID VOLUME module in the SURFER software for different reservoir levels.

\section{SEDIMENTATION RATE CALCULATIONS}

a. Capacity of Koyna reservoir @ RL 642.91(year 1965) 1471.23 Mcum

b. Capacity as per present survey @ RL 642.91(year 2004)

1171.14 Mcum

c. Loss in capacity during a span of 39 years 293.09 Mcum

d. Loss in capacity per year 7.515 Mcum i.e. 751.5 Ha-m

e. Catchment area of Koyna reservoir 891.80 sq.km.

f. Sedimentation rate of Koyna reservoir catchment 84.27 Ham/100 sq.km./year

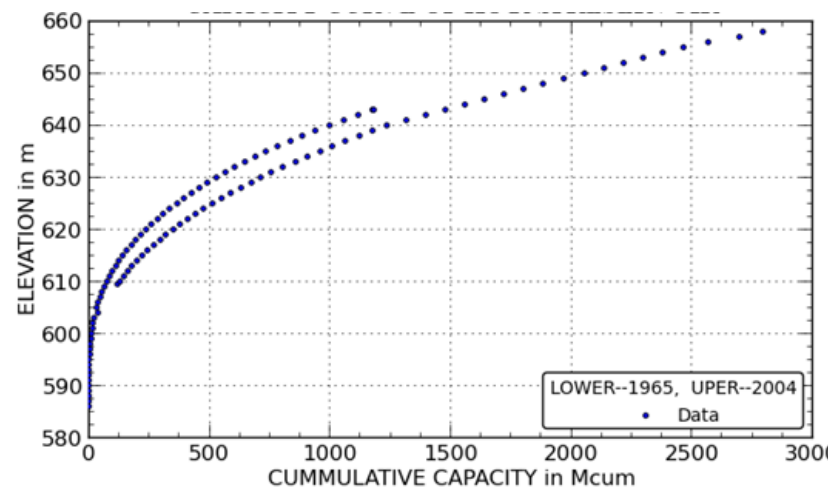

Fig -7: Capacity Curve of Koyna Reservoir

\section{CONCLUSIONS}

The methodology of bathymetric surveys is well developed and is generally seen as the best available method to assess reservoir sedimentation. Further, in assessment of reservoir sedimentation it is important that the reservoir is in operation long enough to include also the rare event and the trap efficiency should be included in calculations. In order to assess the bulk density sufficient sediment samples should be taken. From the results of the survey reservoir capacity table was prepared. Capacity of the reservoir in Mcum for the different elevations ranging from RL $586 \mathrm{~m}$ to RL643 $\mathrm{m}$ is estimated. It is compared with estimated capacity table before first impounding of the reservoir (1965). The comparison graphs are also generated by using the Curve Expert Professional software as shown in figure no. 7. It was observed that at RL 642.91 loss in capacity is
293.09 Mcum in 39 years. It means that sedimentation rate is $84.27 \mathrm{Ham} / 100 \mathrm{sq} . \mathrm{km} /$ year, this value is far more than the rate anticipated during the planning of the reservoir was 6.5 Ham/100 sq.km/year.

\section{ACKNOWLEDGEMENT}

The authors thank to Superintending Engineer, Koyna Construction circle, Satara, Maharashtra Engineering Research Institute, Nashik and Water Resources Department, Government of Maharashtra for providing necessary information. Special thanks by first author to Principal and Management of DKTE Society's Textile and Engineering Institute, Ichalkaranji for their valuable support.

\section{REFERENCES}

[1]. Bathymetric and Sediment Survey of Clinton Lake Reservoir, Douglas County, Kansas, 2009.

[2]. Dipankar Chaudhuri (2006) "Life of Maithon Reservoir on Ground of Sedimentation: Case Study in India", ASCE, Journal of Hydraulic Engineering, Vol. 132, No. 9, 875-880. [3].Issaa E. et.al. (2013) "Sedimentation Processes and Useful Life of Mosul Dam Reservoir, Iraq", Scientific Research, Engineering, 779-784

[4]. J. Toby Minear1 and G. Matt (2009), "Estimating reservoir sedimentation rates at large spatial and temporal scales: A case study of California "Water Resources Research, Vol. 45,

[5]. Jordan Furnans and Barney Austin (2008) "Hydrographic Survey Methods for Determining Reservoir Volume" Science Direct Environmental Modelling and Software, Vol. 23, 139-146.

[6]. Joris de Vente at al. "Evaluation of reservoir sedimentation as a methodology for sediment yield assessment in the Mediterranean: challenges and limitations, Soil Conservation and Protection for Europe"

[7]. Mohammad R. et al. (2014) "Selecting the most Appropriate Method of Basin Sediment Estimation by Sediment Rating Curves at Hydrometric Stations" IJETAE, Vol. 4, Issue 6,

[8]. Sedimentation Study of Shivajisagar Lake of Koyna Dam 1980, 1986, October 2004.

[9].Umesh Kothari (1996) "Erosion and Sedimentation Problems in India", Erosion and Sediment Yield: Global and Regional Perspective, Proceedings of the Exeter Symposium, IAHS Pub. No. 236 